\title{
Profile of Medicolegal Autopsy Cases at Tertiary Care Centre in Belagavi, Karnataka. A One Year Retrospective Study
}

\author{
Khaja Azizuddin Junaidi ${ }^{1}$, Somashekhar S Pujar ${ }^{2}$, Ravindra S Honnungar ${ }^{3}$, Prasanna S Jirli ${ }^{4}$, Vishal V \\ Koulapur ${ }^{2}$, Kashif Ali ${ }^{1}$, Pushpa M.G ${ }^{5}$ \\ ${ }^{1}$ Postgraduate, ${ }^{2}$ Associate Professor, ${ }^{3}$ Professor and HOD, ${ }^{4}$ Professor, Department of Forensic Medicine and \\ Toxicology, KAHER'S J.N Medical College, Belagavi, ${ }^{5}$ Assistant Professor, Department of Forensic Medicine and \\ Toxicology, BIMS, Belagavi
}

\begin{abstract}
Background: The profile of medico legal autopsy cases is important in order to know the death statistics in a region due to unnatural causes and also help to address the demographic needs according to the mortality statistics specific to that region.

Materials and Methods: The present study is a retrospective study of autopsies performed at KAHER'S tertiary care centre K.L.E Hospital, Belagavi, Karnataka India in the year 2017. During this period a total of 159 autopsy cases were conducted. Relevant information and subjective data like age, sex, marital status $\&$ manner of death have been collected from medicolegal autopsy register from January 2017 to December 2017.

Results: Out of 159 cases analyzed, maximum number of autopsies were in the age group of 21-30 years with 55 cases(34.6\%). Majority of victims were males 118(74.2\%). Hindus were majority in number with 147 cases $(92.6 \%)$, married were $122(76.7 \%)$ \& unmarried were 37 cases(23.3\%). In our study $67.9 \%$ were rural residents \& only 32.1\% were urban. Accident, Suicide and Homicide deaths were 110(69.2\%), 37(23.3\%)\& $1(0.6 \%)$ cases respectively. Natural deaths were seen in $6.9 \%$ cases. Maximum number of deaths were due to road traffic accidents with 92 cases (57.9\%) followed by poisoning with 27 cases (17\%). Out of total 159 cases maximum number of autopsy cases 60(37.7\%) were conducted in the month of April to June.

Conclusion: In our present study it is observed that maximum cases were in $3^{\text {rd }}$ decade of life, Males outnumbered females, rural residents were more in number. Hindus being majority formed bulk of cases. RTA, Poisoning \& burns were seen as leading cause of death \&maximum deaths were in the second quarter of the year (April,May\&June).
\end{abstract}

Keywords: Medicolegal Autopsy, Road traffic accidents, Poisoning

\section{Introduction}

Worldwide 55.3 million people die each year ${ }^{[1]}$. About 5.8 million people die each year as a result of injuries. This accounts for $10 \%$ of the total deaths.

\footnotetext{
Corresponding Author-

Dr. Somashekhar S Pujar,

Associate Professor, Department of Forensic Medicine and Toxicology, KAHER'S J.N Medical College, Belagavi-590010
}

Deaths due to unnatural causes includes road traffic accidents, railway accidents, mechanical asphyxia, drowning, accidental fire, electrocution, air crash, stampede, mines disaster, deaths during pregnancy, killed by animals, illicit liquor, snake bites and food poisonng. ${ }^{[2]}$

The rate of unnatural death in India is 39.2 per 1000 live birth per year, while the rate of unnatural deaths in Karnataka is 32.2 per 1000 live birth per year. ${ }^{[3]}$ As per UN report Crude death rate (CDR) between 2015-2020 is $8.1 .^{[4]}$ 
The profile of medico legal autopsy cases is important in order to know the death statistics in a region due to unnatural causes and also help to address the demographic needs according to the mortality statistics specific to that region. It is also necessary in order to prevent the preventable casualties in future and to study the genuine crime rate in the area.

This study aims to set up a profile of deaths owing to unnatural causes, so that we can direct rigorous efforts to curb their incidence. The finding of this study will create awareness among the people and it will also be helpful for law enforcement agencies to make the strategies for prevention of such incidences.

\section{Material and Method}

The present study is a retrospective study of medico legal autopsies conducted at KAHER'S Jawaharlal Nehru Medical College \& KLE Hospital, Belagavi, Karnataka, India from January 2017 to December 2017. Detailed information regarding the circumstances of death was collected from inquest panchanama, hospital records and post-mortem report. During the study period 159 medico legal autopsies were conducted in the mortuary of KLE Hospital. Data like age, sex, marital status, religion, calendar month, residence, causes of death \& manner of death was compiled and analysed. Causes of death were grossly classified as trauma, thermal injuries, violent asphyxia, poisoning and other natural causes.

\section{Results}

A total of 159 medico legal autopsies were conducted during the period of 1 year from January 2017 to December 2017. During this period maximum number of cases were in the second quarter of the year i,e April to June (37.7\%) and minimum number of cases were in the last quarter of the year i,e October to December (22\%). Males outnumbered females (74.2\%) with male to female ratio of $3: 1$. It was observed in the study that the maximum number of autopsy cases i.e. $55(34.6 \%)$ in both sexes were in the age group of 21-30 years followed by the age group of 31-40 years and 4150 years [ Table 1]

Table 1: Age and Sex wise distribution of cases

\begin{tabular}{|l|l|l|l|l|}
\hline Age (years) & Male & Female & Total & Percentage \\
\hline $0-10$ & 1 & 0 & 1 & 0.6 \\
\hline $11-20$ & 9 & 3 & 12 & 7.6 \\
\hline $21-30$ & 43 & 12 & 55 & 34.6 \\
\hline $31-40$ & 17 & 9 & 26 & 16.3 \\
\hline $41-50$ & 19 & 7 & 26 & 16.3 \\
\hline $51-60$ & 18 & 4 & 22 & 13.9 \\
\hline $61-70$ & 6 & 5 & 11 & 6.9 \\
\hline $71-80$ & 4 & 1 & 5 & 3.2 \\
\hline$>80$ & 1 & 0 & 1 & 0.6 \\
\hline Total & 118 & 41 & 159 & 100 \\
\hline
\end{tabular}

Hindus were majority in number with 147 cases $(92.6 \%)$ followed by muslims with $12(7.4 \%)$, married were $122(76.7 \%) \&$ unmarried were 37 cases $(23.3 \%)$. 
Table no-2 depicts that majority of the cases were from rural background i.e, 108 cases $(67.9 \%)$.

Table. 2: Distribution of Cases according to regions of living

\begin{tabular}{|l|l|l|}
\hline Region & No.of Cases & Percentage \\
\hline Urban & 51 & 32.1 \\
\hline Rural & 108 & 67.9 \\
\hline Total & 159 & 100 \\
\hline
\end{tabular}

Table no-3 depicts various manners of death. Accidental deaths were 110(69.2\%), Suicidal 37(23.3\%) and Homicidal deaths were $1(0.6 \%)$.

Table 3: Distribution of cause and manner of death cases.

\begin{tabular}{|l|l|l|l|l|l|l|}
\hline $\begin{array}{l}\text { Cause of } \\
\text { death }\end{array}$ & Accidental & Suicidal & Homicidal & Natural & Total & Percentage \\
\hline RTA & 92 & -- & -- & -- & 92 & 57.9 \\
\hline Poisoning & 05 & 18 & -- & -- & 23 & 14.5 \\
\hline Burns & 06 & 05 & -- & -- & 11 & 6.9 \\
\hline Electrocution & 06 & -- & -- & -- & 06 & 3.8 \\
\hline $\begin{array}{l}\text { Fall from } \\
\text { height }\end{array}$ & 06 & -- & -- & -- & 06 & 3.8 \\
\hline Snake bite & 04 & -- & -- & -- & 04 & 2.5 \\
\hline Hanging & -- & 02 & -- & -- & 02 & 1.3 \\
\hline Drowning & -- & 01 & -- & -- & 01 & 0.6 \\
\hline Lightening & 01 & -- & -- & -- & 01 & 0.6 \\
\hline Assault & -- & -- & 01 & -- & 01 & 0.6 \\
\hline Others & 01 & -- & -- & 11 & 12 & 7.5 \\
\hline Total & 110 & 37 & 01 & 11 & 159 & 100 \\
\hline
\end{tabular}

From Table 4- Maximum number of RTA deaths were due to 2 wheeler vehicular accident (69.6\%), followed by 4 wheeler vehicles $(23.9 \%) \&$ Pedestrian $(4.3 \%)$

Table 4: Distribution of cases according to Type of RTA cases

\begin{tabular}{|l|l|l|}
\hline No. of Cases & Percentage & Type of RTA cases \\
\hline 04 & 4.3 & Pedestrian \\
\hline 64 & 69.6 & 2 Wheeler \\
\hline 22 & 23.9 & 4 Wheeler \\
\hline 02 & 2.2 & Heavy Vehicle \\
\hline 92 & 100 & Total \\
\hline
\end{tabular}


In our study, RTA was most common cause of death $(\mathrm{n}=92,57.9 \%)$, followed by poisoning including snake bite $(\mathrm{n}=27,17 \%) \&$ burns including electrocution and lightening ( $\mathrm{n}=18,11.3 \%)$. Regarding age groups pattern among RTA cases majority of victims were in 21-30 years age group $(n=27)$. The age group in which poisoning were common was between $21-30$ years $(n=11$,
$40.7 \%)$ followed by $41-50$ years $(n=4,14.8 \%)$. Chemical poisoning was the most commonest $(n=23,85.2 \%)$ followed by snake bite $(n=4,14.8 \%)$. In thermal injuries 21-30 years $(n=5,27.8 \%)$ were common. There were 18 cases $(11.3 \%)$ from thermal injuries of which commonest cause was burns $(n=11,61.1 \%)$ followed by electrocution $(n=6,33.3 \%)$ and only one case of lightening was autopsied. [Table 5]

Table 5:Distribution of cause of deaths according to Age

\begin{tabular}{|l|l|l|l|l|l|l|l|l|l|}
\hline Cause of death & $\begin{array}{l}\text { Age } \\
\text { (Years) } \\
\mathbf{0 - 1 0}\end{array}$ & $\mathbf{1 1 - 2 0}$ & $\mathbf{2 1 - 3 0}$ & $\mathbf{3 1 - 4 0}$ & $\mathbf{4 1 - 5 0}$ & $\mathbf{5 1 - 6 0}$ & $\mathbf{6 1 - 7 0}$ & $\mathbf{7 1 - 8 0}$ & $>\mathbf{8 0}$ \\
\hline RTA & 01 & 09 & 27 & 12 & 17 & 12 & 09 & 03 & 02 \\
\hline Poisoning & -- & 02 & 11 & 03 & 04 & 03 & -- & -- & -- \\
\hline Burns & -- & -- & 06 & 05 & -- & -- & -- & -- & -- \\
\hline Electrocution & -- & -- & -- & 06 & -- & -- & -- & -- & -- \\
\hline Fall from height & -- & -- & 02 & -- & -- & 02 & 01 & 01 & -- \\
\hline Snake bite & -- & -- & 02 & -- & 01 & -- & -- & 01 & -- \\
\hline Hanging & -- & -- & -- & 01 & -- & 01 & -- & -- & -- \\
\hline Drowning & -- & 01 & -- & -- & -- & - & -- & -- & - \\
\hline Lightening & -- & -- & -- & 01 & -- & - & -- & - & - \\
\hline Assault & -- & -- & -- & 01 & -- & -- & -- & -- & - \\
\hline Natural & -- & -- & 05 & 02 & 03 & 02 & -- & - & - \\
\hline Total & 01 & 12 & 53 & 31 & 25 & 20 & 10 & 05 & 02 \\
\hline
\end{tabular}

Deaths due to RTA was most common among males $(\mathrm{n}=73,45.9 \%)$ compared to females $(\mathrm{n}=19,11.9 \%)$ Thermal deaths were common in females $(\mathrm{n}=12,66.7$ $\%)$ as compared to males $(n=6,33.3 \%)$. Most of the thermal deaths were suicidal $(\mathrm{n}=11,61.1 \%)$ followed by accidental(38.9\%). Chemical poisoning was most commonly seen in males( $(n=14,60.9 \%)$ as compared to females $(n=9,39.1 \%)$. Maximum number of deaths due to poisoning were suicidal $(\mathrm{n}=23,85.2 \%)$ followed by accidental $(n=4,14.8 \%)$

\section{Discussion}

During the study period a total of 159 cases of medico legal autopsies were performed at KAHER'S J.N Medical College and KLE hospital mortuary. Out of 159 cases maximum number of autopsy cases were in the age group of 21-30 years which is the most productive year in one's life. These findingsare in consistency with findings of Kannan $\mathrm{K}^{[5]}$, Mathiharan $\mathrm{K}^{[5]}$, Curran $\mathrm{WJ}^{[6]}$ \&
ME Bansude ${ }^{[7]}$.

In our study majority of victims were males(74.2\%). Similar findings are seen in studies done by Murthy et $\mathrm{al}^{[8]}$ who studied 150 cases out of which $123(82 \%)$ were males \& 27(18\%) females. Mugadlimath et al ${ }^{[9]}$ studied 64 cases out of which $39(61 \%)$ were males \&25(39\%) females.

The reason being that as males are bread earners and females usually doing household work, which makes the males more vulnerable to accidents, violence and stress $\&$ also males predisposed for risk taking behaviour.

In our study $92.6 \%$ were Hindus, and $7.4 \%$ were Muslims.Similar findings are observed in studies by Kannan $\mathrm{K}^{[5]}$, Mathiharan $\mathrm{K}^{[5]}$ and Curran $\mathrm{WJ}^{[6]}$. Rural residents were $67.9 \%$ and only $32.1 \%$ were from Urban. This finding is contradicting to results of other studies done by Radhakrishna $\mathrm{KV}^{[13]}$ et al and Patel $\mathrm{JB}^{[14]}$ et al in which Urban residents were in majority.This difference 
is due to our centre serves more rural population.

Deaths due to road traffic accidents \& its complications constituted majority of cases $57.9 \%$ followed by poisoning $17 \%$ and burns $11.3 \%$.Similar findings are observed in studies done by $\mathrm{K}$ Awdesh et $\mathrm{al}^{[15]}$ and ME Bansude. ${ }^{[7]}$.The reason being that our centre being tertiary care hospital, most of the accident cases are referred to our hospital including from rural areas.

According to month wise distribution of cases, findings of our study showed more number of cases between April to June. Similar findings are seen in studies by Patel et al ${ }^{[14]}$ and Awdesh et al ${ }^{[15]}$.

\section{Conclusion}

Study conducted at KAHER'S Jawaharlal Nehru Medical College \& KLE Hospital Belagavi, to know the profile of medico legal autopsies during a period of one year from January 2017 to December 2017 comprising a total of 159 medicolegal autopsies. In our study we found that majority of cases were in $3^{\text {rd }}$ decade of life, males outnumbered females, rural residents were more in number, Hindus being majority in number formed bulk of cases, RTA, Poisoning and burns wereseen as leading cause of death, among road traffic accidents 2 wheeler accidents were more in number. Maximum number of cases were seen in the period between April-June. This study helps to interpret different types of medico legal autopsy cases, thereby providing an insight to the policy makers, law custodians, and the community to look into the specific aspects of the cases and then to take proper measures to reduce mortality.

\section{Conflict of Interest- None}

\section{Source of funding- Self}

Ethical Clearance- Institutional Ethical Committee approval/ Clearance taken

\section{References}

1. World wide death statistics http://www.ecology. com>Birth-death-rates Accessed on 6-7-2018

2. IANS inputs http://www.ians.in Accessed on 6-72018
3. www.icmr.nic.in/disease burden/ KarnatakaDiseaseBurdenProfile.pdf cited on $10 / 08 / 2018$

4. "UN data-record view-Crude death rate (deaths per 1,000 population)".'Accessed on 09-01-2019

5. Kannan K, Mathiharan K. Ed. In: Modi-A textbook of Medical Jurisprudence and Toxicology. $24^{\text {th }}$ Ed.LexisNexis Butterworth's Nagpur: 2012.p.293,295,297,360.

6. Curran WJ. The Medico-legal autopsy and Medicolegal investigation. Bull N Y Acad Med 1971 July;47(7):766-75

7. ME Bansude et al. Trends of unnatural deaths in latur district of Maharashtra. Journal of Forensic Medicine,Science and Law.2012; 21:2.

8. Murthy MSN, Dutta BN, Ramalingaswami V. Coronary atherosclerosis in North India (Delhi Area). J PatholBacteriol 1963;85:93-101.

9. Mugadlimath A, Kadagoudar S, Sheelvant S, Bambeshwar K. Profile of medico legal autopsy cases at tertiary care centre in Bagalkot, Karnataka. Indian Journal of Forensic Medicine and Pathology.2017;10(2):63-66.

10. Bhullar DS, Oberoi SS, Aggarwal OP et al. Profile of Unnatural deaths (between 18-30 years of age) in GMCH Patiala,(India). JFMT. 1996;13(3):5-8.

11. Sharma BR. Trends of Poisons and Drugs used in Jammu. Journal of Forensic Medicine and Toxicology. 1996;13(2):7-9.

12. Singh Prabjot. Alarming rise in fatalities The Tribune, 2000 Aug 19:1 \& 22.

13. Radhakrishna KV, Makhani CS, Sisodiya CN, Chourasia S, Sarala M, Khan RN. Profile of medicolegal autopsies at tertiary medico legal centre in southwestern India. Int $\mathrm{J}$ Healthcare Biomed Res. 2015;3(2):70-5.

14. Patel JB, Chandegara PV, Patel UP, Parkhe SN, Govekar G. Profile of autopsy cases at New Civil Hospital, Surat, a retrospective study. Int J Med Sci Public Health. 2016;5:10-13.

15. K Awdhesh, Pondey SK, Singh TB. A descriptive study on trend of unnatural deaths in Varanasi,India. International Journal of Current Research. March2015;7:14041-44. 